\title{
Percurso formativo na Rede de Atenção Psicossocial: Inovação e transformação nas práticas em saúde mental*
}

\author{
Larissa Weber ${ }^{1,2,3}$ \\ (D) https://orcid.org/0000-0002-5278-245X \\ Roger dos Santos Rosa ${ }^{4}$ \\ (D) https://orcid.org/0000-0002-7315-1200 \\ Marina da Silva Sanes $3,5,6$ \\ (D) https://orcid.org/0000-0002-2367-6148 \\ Jaime Alonso Caravaca-Morera ${ }^{7}$ \\ (iD) https://orcid.org/0000-0002-6647-217X
}

\footnotetext{
A publicação deste artigo na Série Temática "Recursos Humanos em Saúde e Enfermagem" se insere na atividade 2.2 do Termo de Referência 2 do Plano de Trabalho do Centro Colaborador da OPAS/OMS para o Desenvolvimento da Pesquisa em Enfermagem, Brasil. Artigo extraído da dissertação de mestrado "Percursos formativos na rede de atenção psicossocial (RAPS): intercâmbio entre experiências" no município de Guaíba-RS", apresentada à Universidade Federal do Rio Grande do Sul, Porto Alegre, RS, Brasil.

1 Universidade Federal de Santa Catarina, Programa de PósGraduação em Saúde Coletiva, Florianópolis, RS, Brasil.

2 Prefeitura Municipal de Guaíba, Secretaria Municipal de Saúde, Guaíba, RS, Brasil.

${ }_{3}^{3}$ Bolsista da Coordenação de Aperfeiçoamento de Pessoal de Nível Superior (CAPES), Brasil.

${ }^{4}$ Universidade Federal do Rio Grande do Sul, Programa de Pós Graduação em Ensino na Saúde, Porto Alegre, RS, Brasil.

${ }_{5}^{5}$ Universidade Federal de Santa Catarina, Programa de PósGraduação em Enfermagem, Florianópolis, RS, Brasil.

${ }^{6}$ Bolsista do Programa de Excelência Acadêmica (PROEX), Brasil.

Universidad de Costa Rica, Facultad de Medicina, San José, SJ, Costa Rica.
}

Objetivo: descrever as transformações decorrentes da participação de trabalhadores da Secretaria Municipal de Saúde de Guaíba/RS no projeto "Percursos Formativos na Rede de Atenção Psicossocial: Intercâmbio entre experiências", do Ministério da Saúde. Métodos: estudo qualitativo, descritivo, em que foram realizadas entrevistas semiestruturadas individuais com 22 participantes e consultas a documentos pertinentes ao projeto. Utilizou-se análise de conteúdo de Bardin. Resultados: apresentados em dois eixos: "Intercâmbio como estratégia inovadora na formação", "Ressignificação das práticas no campo da saúde mental". Identificaram-se mudanças nos processos de trabalho decorrentes do aumento da visibilidade do campo da saúde mental e melhorias na atenção aos usuários, com destaque para práticas alinhadas à humanização do cuidado. Detectou-se incremento na motivação dos trabalhadores e maior articulação entre os serviços da rede. O projeto apresentou características inovadoras de formação e sua execução foi decisiva nas transformações que já estavam em curso. A pesquisa evidenciou a relação entre experiências de formação e processos de cuidado mais afeitos a uma produção de saúde crítica, reflexiva, criativa e emancipatória. Conclusão: desvelase desenvolvimento de forte e duradouro senso de crítica e de necessidade de inovação em saúde mental, que parecem ter emergido com mais vigor durante a realização do projeto.

Descritores: Sistema Único de Saúde; Saúde Mental; Educação Continuada; Humanização da Assistência.

\section{Como citar este artigo}

Weber L, Rosa RS, Sanes MS, Caravaca-Morera JA. Training path in the Psychosocial Care Network: Innovation and transformation in mental health practices. SMAD, Rev Eletrônica Saúde Mental Álcool Drog. 2021 jul.-set.;17(3):37-46. doi: https://dx.doi.org/10.11606/issn.1806-6976.smad.2021.169923 


\section{Training path in the Psychosocial Care Network: Innovation and transformation in mental health practices}

Objective: to identify and describe changes resulting from the participation of workers from the Municipal Health Department of Guaíba/RS in the project entitled "Training Path in the Psychosocial Care Network: Exchange between experiences", from the Ministry of Health. Method: a qualitative and descriptive study in which individual semi-structured interviews were conducted with 22 participants, as well as consultations to documents relevant to the project. Bardin content analysis was used. Results: presented in two axes: "Exchange as an innovative training strategy" and "Resignifying the practices in the field of mental health". Changes in work processes were identified, as a result of increased visibility of mental health field and improvements in care, with emphasis on practices aligned with the humanization of care. There was an increase in the workers' motivation and articulation among the services of the network. The project presented innovative training characteristics and its execution was decisive in the transformations that were underway. The research showed the relation between training experiences and care processes more related to a critical, reflective, creative and emancipatory health production. Conclusion: the development of a strong sense of criticism and the need for innovation in mental health was revealed, which emerged with more vigor during the project.

Descriptors: Unified Health System; Mental Health; Education, Continuing; Humanization of Assistance.

\section{Recorrido formativo en la Red de Atención Psicosocial: Innovación y transformación en las prácticas en salud mental}

Objetivo: identificar y describir las transformaciones provenientes de la participación de trabajadores de Guaíba/RS en el proyecto "Recorrido Formativo en la Red de Atención Psicosocial: Intercambio entre experiencias" del Ministerio de Salud. Métodos: estudio cualitativo descriptivo. Se realizaron entrevistas semiestructuradas entre 22 participantes y consultas sobre documentos relevantes para el proyecto. Además, el análisis de contenido de Bardin orientó la reflexión. Resultados: se presentaron dos ejes: "Intercambio como estrategia innovadora de formación", "Resignificación de las prácticas en el campo de salud mental". Se identificaron cambios en los procesos laborales provenientes del aumento de la visibilidad del campo de la salud mental y mejorías en la atención de usuarios con destaque para prácticas alineadas a la humanización del cuidado. Se detectó incremento en la motivación de trabajadores y mayor articulación entre los servicios de la red. El proyecto presentó características innovadoras de formación y su ejecución fue decisiva en la transformación de la Red que estaba en curso. La investigación evidenció la relación entre las experiencias de formación y los procesos de cuidado más vinculados a una producción de salud crítica, reflexiva, creativa y emancipadora. Conclusión: se devela el desarrollo firme y duradero del sentido crítico como también de la necesidad de innovación en salud mental que parecen haber emergido con mayor vigor durante la realización del proyecto.

Descriptores: Sistema Único de Salud; Salud Mental; Educación Continua; Humanización de la Atención. 


\section{Introdução}

As mudanças da atenção ao sofrimento psíquico em suas diversas formas, processo conhecido como Reforma Psiquiátrica (RP), ganharam impulso no Brasil principalmente a partir de 1980. A RP difundiu no país uma concepção de cuidado em saúde mental que prescinde de instituições fechadas e disciplinadoras, apostando no acolhimento e no cuidado nos territórios de vida das pessoas ${ }^{(1-2)}$. Na medida em que os objetivos iniciais da RP foram fortalecidos, a Política Nacional de Saúde Mental abarcou também a atenção à saúde mental de crianças e adolescentes e as estratégias de enfrentamento ao uso prejudicial de álcool e outras

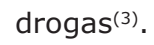

Em decorrência deste processo, e atendendo ao disposto na Lei $10.216 / 2001^{(4)}$, a criação de serviços substitutivos ao hospital psiquiátrico foi fomentada. Tal processo ocorreu a despeito da constante restrição orçamentária presente no contexto do Sistema Único de Saúde (SUS) $)^{(5)}$. A expansão dos serviços trouxe à tona a necessidade de promover a articulação do trabalho em rede no campo da saúde mental.

Como forma de consolidar a articulação, em 2011, o Ministério da Saúde (MS) instituiu a Rede de Atenção Psicossocial para pessoas com sofrimento ou transtorno mental e com necessidades decorrentes do uso de crack, álcool e outras drogas (RAPS). A RAPS é constituída por serviços de atenção básica ( $A B)$, atenção psicossocial especializada, urgência e emergência, hospitalar e por serviços residenciais de caráter transitório, residenciais terapêuticos e de reabilitação psicossocial(6).

Dois anos após a instituição da RAPS, foi lançado o projeto "Percursos Formativos na RAPS: Intercâmbio entre Experiências e Supervisão Clínico-Institucional". Trata-se de uma estratégia de Educação Permanente em Saúde (EPS) baseada em uma ação de intercâmbio para profissionais da RAPS, a partir da integração de municípios com redes preceptoras (consolidadas) e redes em formação (em consolidação). Fundamenta-se na troca de experiências e ampliação das possibilidades de intervenção, a partir da convivência de profissionais com a realidade de outros municípios e realização de oficinas de atualização ( $1^{a}$ etapa) e da supervisão clínicoinstitucional ( $2^{\mathrm{a}}$ etapa).

O município de Guaíba/RS, com cerca de 100 mil habitantes, situado a $30 \mathrm{~km}$ de Porto Alegre, foi selecionado para participar do projeto como rede em formação, apresentando necessidade de qualificação nas demandas envolvendo o consumo de álcool e outras drogas. Na época, o município processava uma remodelação dos serviços, com o propósito de se adequar à Portaria No 3088, que institui a RAPS(6).

Até 2014, ano em que iniciou o projeto, o cuidado em saúde mental em Guaíba era centrado em um
Centro de Atenção Psicossocial tipo II (CAPS II) e no antigo Ambulatório de Saúde Mental. A partir da readequação da equipe do Ambulatório, foi possível implementar o CAPS AD em 2015, mesmo ano em que foi pactuada a implantação de um CAPS IJ (infantojuvenil), implementado em 2018. Paralelamente, investiu-se na descentralização do cuidado em saúde mental da atenção secundária para a $A B$, acompanhado do fortalecimento do matriciamento em saúde mental. No mesmo período, foram implantadas as primeiras equipes de Estratégia de Saúde da Família e ocorreu o fechamento do único hospital da cidade, o qual oferecia leitos em saúde mental. Atualmente o acesso a leitos hospitalares em saúde mental ocorre por meio da Central de Regulação de Leitos, gerenciada pelo Estado do RS, que faz a adequação entre a demanda por internação e os leitos ofertados pelo SUS.

O município de Santo André, região metropolitana de São Paulo, foi designado como rede preceptora para Guaíba e mais nove cidades. Em duplas ou trio, pelo menos 20 profissionais da RAPS de cada um destes municípios, de diferentes formações, realizaram intercâmbio de um mês em Santo André, com início em maio de 2014.

Considerando a relevância de avaliar políticas e programas em saúde para qualificação do sistema de saúde e minimização de crises $^{(7)}$, foi realizado um estudo acadêmico que avaliou a execução da primeira etapa do Percurso Formativo (PF) ocorrido em Guaíba. Dentre os resultados encontrados, destaca-se a percepção dos participantes quanto à formação proporcionada pelo intercâmbio e quanto às modificações ocorridas nos processos de trabalho(8).

O presente artigo justifica-se pela necessidade de compreender como se deu a troca de experiência entre os trabalhadores e quais transformações na RAPS de Guaíba se efetivaram com o intercâmbio. Desse modo, busca-se descrever as mudanças ocorridas a partir das experiências do intercâmbio e como a experiência educativa afetou os participantes do percurso e a RAPS de Guaíba, discutindo como o projeto caracterizou-se enquanto uma boa prática de formação, ensino e investigação em Saúde Mental, Álcool e Drogas.

\section{Método}

Trata-se de estudo qualitativo, de cunho descritivo, realizado no município de Guaíba/RS, no contexto da RAPS e do projeto "Percursos Formativos na RAPS: Intercâmbio entre experiências", no período de 2016 a 2017.

A população do estudo foi constituída a partir do seguinte critério de inclusão: ter participado do intercâmbio como servidor de Guaíba. Como critério de exclusão, estabeleceu-se: apresentar condição que impossibilitasse a participação na pesquisa, seja por 
afastamento (férias, licença ou outro motivo), seja por envolvimento direto na execução da pesquisa.

As atas do Conselho Municipal de Saúde, das assembleias dos CAPS e do Grupo Condutor da RAPS de Guaíba (constituído por gestores e representantes dos serviços da RAPS) foram utilizadas para identificar os profissionais que participaram do intercâmbio, bem como seu período de execução. O edital previa a participação de 20 trabalhadores de cada rede em formação. No entanto, ao longo da execução do projeto, o Grupo Condutor identificou a disponibilidade de recursos financeiros para ampliar o total de participantes. Assim, o número de intercambistas passou dos 20 inicialmente previstos para 23. O recrutamento destes profissionais para o intercâmbio se deu no âmbito das atividades do Grupo Condutor.

Identificados os intercambistas, fez-se a eles o convite para participar da pesquisa. Todos concordaram, sendo que nenhum, exceto uma trabalhadora que é também autora da pesquisa, estava impossibilitado de participar. Portanto, aplicando-se os critérios de inclusão e de exclusão, chegou-se a uma população de 22 profissionais. Estes caracterizaram-se por serem concursados, majoritariamente do sexo feminino $(n=21)$. Seis possuíam formação de nível médio (quatro técnicas de enfermagem, uma artesã e uma técnica administrativa) e 17 apresentavam formação de nível superior (sete enfermeiros, sete psicólogas, duas assistentes sociais e uma terapeuta ocupacional). No que se refere ao cenário de atuação, 16 atuavam nos serviços especializados, seis na $A B$ e uma no Serviço de Pronto Atendimento.

A coleta de dados ocorreu por meio de entrevistas semiestruturadas individuais, norteadas por um roteiro. As perguntas organizaram-se em torno da compreensão dos participantes acerca do projeto, seu planejamento e execução, influências do intercâmbio sobre a formação/ atuação em saúde mental, mudanças nos processos de trabalho e benefícios para a RAPS de Guaíba. As entrevistas, com duração média de 30 minutos, foram realizadas em salas reservadas, gravadas em áudio e transcritas de forma literal. O material foi submetido à análise de conteúdo, apoiada nas etapas de pré-análise; exploração do material; tratamento dos resultados, inferência e interpretação(9).

A pesquisa obteve aprovação do Comitê de Ética da Universidade Federal do Rio Grande do Sul (Parecer 1.571.068 - CAAE: 52639116.7.0000.5347) e aceite institucional da Secretaria Municipal da Saúde de Guaíba. A anuência dos participantes deu-se pela assinatura do Termo de Consentimento Livre e Esclarecido (TCLE), onde constavam: objetivo do estudo, forma de coleta de dados, garantia de preservação da identidade dos participantes e do sigilo dos dados. Foi designada sequência alfanumérica (E1 a E22) para garantir o anonimato dos participantes.

\section{Resultados}

Os intercambistas de Guaíba inseriram-se na RAPS de Santo André entre maio de 2014 e outubro de 2015. Em agosto de 2015 ocorreu o intercâmbio de três trabalhadores e um usuário de Santo André para conhecer a RAPS de Guaíba e ajudar a promover oficinas de capacitação no município. As percepções dos intercambistas participantes do estudo serão apresentadas a partir de dois eixos:

\section{Intercâmbio como estratégia inovadora na formação}

Os dados coletados indicam que o aprendizado com a inserção in loco estimulou a busca por conhecimentos teóricos relacionados à RP e à Política de Saúde Mental, promovendo uma dialética entre teoria e prática, que seguiu viva após o término do intercâmbio: Mexeu bastante, assim, de eu perceber aonde eu preciso reforçar mais, quais são as práticas que eu faço que vão ao encontro da proposta nacional e que outras práticas que eu preciso repensar, [...] estudar, onde eu preciso me fortalecer. Porque lá prá onde nós fomos eles são muito apropriados [...] das normas, das leis, da política (E3).

Entre os trabalhadores mais identificados com a saúde mental, constatou-se um processo de reafirmação dos princípios da RP: A gente conheceu as pessoas que realmente vivenciaram a Reforma Psiquiátrica e isso faz com que a gente repense o trabalho [...]. E ver de fato a Reforma acontecendo, como a gente viu o hospital [psiquiátrico] de fato sendo fechado. [...] Então a gente viu na prática o que os livros falam (E8).

O intercâmbio oportunizou uma análise das próprias condições de trabalho, possibilitando reflexões sobre o serviço de atuação e os demais pontos de atenção da rede: A gente veio de lá eu acho que com mais ânimo, com mais gás, de tentar colocar aquelas coisas que a gente viu que deram certo lá e de valorizar mais o que tá dando certo aqui também (E5).

Além de propiciar o conhecimento de equipamentos diferentes, a inserção na rede preceptora proporcionou a realização de trocas entre os envolvidos. A ideia de "troca" revelou-se uma "palavra-chave" entre os entrevistados: Acho que trocar com os profissionais de lá, com os usuários, foi superimportante, mas isso de também trocar com quem vinha de outras cidades e até mesmo com quem era da nossa cidade (E22).

Outrossim, o campo da saúde mental ganhou visibilidade com a execução do projeto: Acho que esse intercâmbio favoreceu prá, vamos dizer, popularizar ou difundir a saúde mental na Secretaria da Saúde (E10). A realização das oficinas em Guaíba, ao ampliar 
o alcance para outros profissionais, contribuiu para expandir a saúde mental além do setor saúde: E o que foi bacana nessa interlocução, assim, foi que outros serviços também participaram. A rede de saúde, de assistência social, de educação, tanto que depois isso repercutiu muito, [...] deu uma clareada, e quando pessoas vêm de fora, parece que potencializa isso (E7).

Ao lançar um olhar para as demandas relacionadas ao consumo de álcool e outras drogas, percebeu-se que alguns profissionais foram surpreendidos pela riqueza de intervenções que podem ser feitas na área. A experiência proporcionada pelo Consultório na Rua teve expressivo destaque no relato dos participantes: Lá eles têm o Consultório na Rua, prá dependência química, mas eles têm todo esse trabalho já bem constituído, assim. De fazer abordagem, tá trabalhando com a pessoa que não vai no Posto de Saúde, que não vai no serviço de atenção psicossocial (E7).

Por fim, percebeu-se considerável elevação da autoestima dos trabalhadores e das equipes a partir da participação no intercâmbio: Nesses quinze anos que eu estou aqui, eu nunca tinha visto nada igual. [...] Então eu acho é uma valorização [...] do funcionário, do serviço e do município, dos usuários (E18). Constatou-se que o intercâmbio repercutiu na formação dos participantes para além da esfera profissional: Eu acho que [foi] uma das melhores experiências que eu tive na minha vida, eu digo sempre prá todo mundo [...] eu não sei se eu levei mais prá minha vida profissional ou prá minha vida pessoal, mas prá minha vida pessoal foi uma formação maravilhosa (E17).

\section{Ressignificação das práticas no campo da saúde mental}

O projeto apostava na ampliação das possibilidades de intervenção dos participantes, a partir da convivência com outras realidades, demonstrando que o intercâmbio inspirou a transformação das práticas: $E$ todo mundo [...] voltou tentando implantar alguma coisa que viu lá. [...] Não sei da Saúde Mental, mas da Atenção Básica todo mundo [...]. Então eu acho que a estada lá, ver como funciona o serviço de um outro lugar [...] abriu janelas prá que a gente repensasse prá, de alguma forma, aplicar aqui também (E21).

Entre os participantes, até então menos familiarizados com a área, percebeu-se menos resistência e superação de antigos preconceitos, estigmas e estereótipos: Com paciente psiquiátrico eu tava tendo um pouco de resistência e eu tenho um outro olhar agora. [...] Eu acho que eu sou mais resolutiva agora, acho que eu consigo enxergar as coisas de uma outra forma, sou mais humana (E13).

Evidenciou-se uma ampliação no escopo das práticas executadas: A rede tá sendo mais acolhedora, aceitando atender os usuários de saúde mental e $A D$, porque antes encaminhavam direto pro CAPS, não escutavam, não ouviam. Tá atendendo melhor a crise, sendo mais participativa, participando mais dos encontros da rede (E8). Ainda que não de forma uniforme, reconheceu-se maior implicação dos serviços na atuação perante a crise: Em alguns lugares dessa rede, os serviços do território, eles conseguem segurar mais uma crise ou buscar uma orientação, conseguem acolher aquela crise. Mas acho que são lugares muito específicos, [...] um avanço maior da saúde mental sobre o território é que vai, aos poucos, mudando isso (E4).

Foram identificadas, especialmente nos CAPS, modificações nos processos de trabalho relacionadas com elementos da Política Nacional de Humanização(10). No que se refere ao acolhimento, sublinha-se o reconhecimento da necessidade em saúde do outro: Eu acho que foi fundamental na minha acolhida ao paciente psiquiátrico, sabe, eu fazia de uma forma diferente, eu não tinha tanta paciência, eu não ouvia tanto. Hoje eu já tenho um outro olhar (E13).

Em relação à ambiência, parte-se da premissa de que o espaço físico pode corresponder a um espaço social: Que antes [...] não tinha espaço onde fazer ambiência, não tinha como. E agora não. Muito a gente conseguiu. Fica em ambiência, fica participando de oficinas, então eu acho que diminuiu até as internações (E5).

Ancorado na diretriz do apoio matricial, vislumbra-se um processo de trabalho que dimensiona a integração e o apoio entre profissionais, equipes e serviços: Hoje o matriciamento, [...] faz muito sentido, não só prá gente, [...] faz sentido prá quem tá lá na Atenção Básica, prá quem tá no Pronto Atendimento, prá quem é da rede (E6).

Já nos processos de gestão, salienta-se um transcurso de desenvolvimento e crescimento por parte destes atores da política de saúde: Acho que uma grande força é na questão da gestão, desse crescimento de gestão em saúde mental, que tá nos trazendo benefícios prá rede (E2).

O Projeto Terapêutico Singular (PTS) revela-se como uma ferramenta que passa a fazer parte da prática profissional: Plano terapêutico, como é que é, PTS. Singular. Porque eu não sabia, não fazia ideia do que era, até achava que era reposição hormonal. [...] Foi o que eu aprendi de mais novo, até agora tô fazendo aqui no posto (E21).

No princípio da autonomia/protagonismo, evidencia-se a reflexão sobre a capacidade de participação dos usuários como uma aposta a ser alcançada: Claro que eu não vou esperar que os nossos usuários aqui do Rio Grande do Sul tenham a mesma postura dos usuários do Grande $A B C$, porque a história sócio-política é outra [...]. Mas de ver a forma participativa dos usuários lá, que é possível. [...] Acredito que isso veio contribuir, assim, até com a minha motivação (E18).

No exercício da clínica ampliada, ao centralizar a singularidade do sujeito e a complexidade do processo saúde-doença, a tomada de decisões faz-se de forma compartilhada e compromissada com a autonomia e a saúde dos usuários: Que vai prá além desse PTS formalizado [...], tem um dia que a pessoa [...] não quer elaborar nada. Ela quer só poder sentar do lado de alguém e ser ouvida, ser abraçada, ter um ombro (E3). 
Importa enfatizar que o intercâmbio foi decisivo na consolidação das mudanças que estavam em curso: Logo em seguida que nós voltamos, já vinha um movimento de extinção do Ambulatório de Saúde Mental e eu me senti mais fortalecida [...] prá esses passos que vinham acontecendo (E9). A mudança mais destacada pelos participantes foi a implementação do CAPS AD. O fato de ele ter sido implantado durante o $\mathrm{PF}$ reforçou seu alinhamento às práticas antimanicomiais: Com atitudes menos punitivas, menos julgadoras. [Os profissionais do CAPS AD] tão sendo mais ousados, [...] pensando mais em estratégias de moradia alternativas. $O$ cuidado também em relação à ambiência, o usuário vai chegar lá a qualquer momento que vai ser atendido, acho que qualificou realmente o cuidado (E8).

\section{Discussão}

Uma vez que o PF adotou o intercâmbio como instrumento de formação, foi possível aos trabalhadores desenvolverem habilidades calcadas nos pressupostos do intercâmbio como prática cultural, que remonta ao período das grandes guerras mundiais e tem como premissa a difusão do respeito e a redução da intolerância entre os $\operatorname{povos}^{(11)}$, valorizando o respeito às diferenças, superação de antigos preconceitos e desenvolvimento de empatia e alteridade.

O intercâmbio possibilitou experenciar o ato de ser acolhido e de criar vínculos com pessoas e locais até então desconhecidos. Não por acaso, uma das principais modificações relatadas relaciona-se à qualificação do acolhimento nos locais de trabalho. Percebe-se, portanto, que as transformações de natureza pessoal desencadeadas pelo intercâmbio apresentam estreita relação com as mudanças de caráter prático.

Assim, os benefícios da formação não ficaram restritos ao aprimoramento técnico, que poderia ser atingido em uma educação permanente de menor proporção. As transformações operadas pelo intercâmbio refletiram simultaneamente nos processos de trabalho (qualificação do atendimento ofertado, adequação dos serviços segundo os preceitos da RP) e no âmbito pessoal (elevação da motivação, autoestima, satisfação) dos participantes.

O incremento motivacional dos trabalhadores para lidar com as rotinas de trabalho, por si só, seria suficiente para reconhecer o êxito da primeira etapa do PF. Quanto maior a satisfação do trabalhador, maiores as possibilidades de promover melhorias no campo de atuação(12). Infere-se, assim, que é pela mobilização de recursos emocionais que se dá a disposição à mudança.

A formação em serviço, preconizada no $\mathrm{PF}$, tende a estabelecer mais mudanças de comportamento nos trabalhadores quanto mais for interativa, contextualizada e baseada em problemas reais(12). A necessidade de investir em uma educação problematizadora, que supere os tradicionais atos de transferência de conhecimento, à maneira de uma concepção bancária, foi uma das bandeiras levantadas por Freire. A formação deve considerar a visão de mundo dos indivíduos (vivências, saberes, formas de interpretar a realidade) como ponto de partida no processo de ensino(13).

Posto que considera o trabalho como fonte de conhecimento e aprimoramento, a proposta pedagógica por detrás do PF, reconhecido aqui como uma estratégia inovadora de EPS, fundamenta-se em uma concepção de educação freireana. A ênfase no aprendizado a partir das experiências de encontro, de modo que cada participante contribua com sua história de vida e experiências pregressas, evidencia o alinhamento do PF com o entendimento freireano de que o aprendizado é um ato dialógico em que as pessoas se educam em comunhão, mediatizadas pelo mundo. Ademais, como proposta educativa que valorizou a problematização, outro efeito alcançado pelo PF foi o fomento à construção de uma consciência crítica que favoreceu mudanças das práticas $^{(13)}$.

Autores de outros campos do conhecimento ajudam a explicar como a experiência prática contribui para a produção de conhecimento. Na perspectiva dos biólogos Maturana e Varela(14), "todo fazer é um conhecer e todo conhecer é um fazer". A partir da interação do organismo com o meio, tanto um quanto o outro se modificam mutuamente - processo conhecido como autopoiese $^{(14)}$.

Transposto para o campo da Educação, este entendimento permite inferir que a educação é influenciada pelo contexto, ao mesmo tempo em que o transforma. Ou que, na aprendizagem voltada para o trabalho, o trabalhador sofre interferências ao mesmo tempo em que influencia os processos produtivos $^{(15)}$.

Quando alguma nova interação tira o sujeito da rotina, a exemplo do intercâmbio, é concedida ao sujeito a oportunidade de refletir sobre suas certezas, fruto das tradições estabelecidas pelo grupo social a que pertence. Nesse processo, o sujeito se questiona reconstrói suas verdades e é concomitantemente transformado por elas. Dito de outra maneira, "todo ato de conhecer faz surgir um mundo"(14).

O recurso de criar um "novo mundo" mostra-se especialmente relevante no âmbito das demandas relacionadas ao uso de álcool e outras drogas, por ser esse um campo que ficou à margem da agenda principal da RP por um longo período. Somente a partir dos anos 2000 identifica-se maior aproximação do tema ao campo da saúde pública, em geral, e da saúde mental, em particular(16).

As experiências das últimas décadas deflagraram uma "guerra às drogas" que resultou em ações coercitivas de baixa efetividade, na escalada da violência e na ascensão 
de organizações criminosas. Um "novo mundo", na ótica dos problemas relacionados ao uso de drogas, traduz-se por um novo referencial que busca o aumento da coesão social como forma de enfrentamento ao problema ${ }^{(17)}$. As marcas destacadas pelos entrevistados a partir da imersão em serviços como o Consultório na Rua, por exemplo, não deixam dúvidas quanto à potência desvelada por esse novo referencial.

A imersão em Santo André permitiu aos participantes não só conhecer diferentes pontos de atenção e estratégias de trabalho, como cooperar horizontalmente com as equipes e, no retorno, compartilhar as boas práticas reconhecidas. Assim, o artifício do intercâmbio revelou-se promissor como método de divulgação e valorização do conhecimento produzido nos serviços.

Também se mostrou promissor ao possibilitar o avanço da saúde mental além dos muros (concretos ou simbólicos) institucionais do campo, consolidando os pressupostos gravados na RP. Uma mudança dessa ordem majora o trabalho na área, reforça a autoestima profissional e ajuda a combater preconceitos ainda existentes. Destaca-se que "o combate ao estigma é um importante fator para reduzir também o gap de mortalidade da população com transtornos mentais, desde que os próprios serviços de saúde tendam a negligenciar por sua causa a assistência adequada e oportuna a essa população"(5).

Os achados no município de Guaíba apresentam-se coerentes com a avaliação nacional do projeto realizada pela coordenação do PF com 740 intercambistas de diversos municípios. Segundo essa avaliação, o projeto cooperou com a transposição do paradigma asilar para o psicossocial (para 58\%); apresentou a história da RP (47\%); fez refletir sobre a humanização do cuidado em saúde mental (44\%); colaborou no aprofundamento teórico (23\%) e divulgou as portarias da RAPS (15\%). Além disso, $71 \%$ dos participantes da referida avaliação afirmaram ter aprendido novas práticas, como: organização do PTS, atuação do profissional de referência, efetivação de reuniões de equipe e assembleias, organização de fóruns sobre saúde mental, desenvolvimento de atividades no território e com as famílias, realização de visitas domiciliares e matriciamento e proposição de ações voltadas para autonomia(18).

Tais elementos também apareceram nos resultados do presente estudo, haja vista os relatos de mudança de postura em relação aos usuários dos serviços, fomento ao compartilhamento do cuidado e empenho na reconfiguração da RAPS em Guaíba. Achados que se mostram promissores, na medida em que estudos recentes vêm destacando a importância da potencialização da rede para a qualificação do cuidado(19-21).

Os desdobramentos das práticas de cuidado em saúde mental ora revelados, a partir da associação entre os processos de educar e cuidar, remetem aos pressupostos que conectam atos educativos e atos cuidativos. Entre eles: oportunidade de encontro dialógico com o outro (visita a outra rede), desenvolvimento de processo de conscientização sobre a realidade (trabalho na RAPS em Guaíba), possibilidade de integração entre processo educativo e de trabalho (agir-refletir-agir na RAPS municipal), anúncio de pertencimento à rede (implicação na RAPS) e aposta criativa de mudança de realidade (produzir-se e produzir a RAPS) $)^{(13)}$.

Já a identificação das diretrizes da PNH demonstra como as políticas de saúde podem ser transversalizadas e operacionalizadas na RAPS. Escuta qualificada, organização de ambientes confortáveis, apoio técnicopolítico institucional, protagonismo e corresponsabilidade são elementos consoantes à RP e à necessidade de pautar o cuidado em saúde mental pela singularidade do sujeito, pela complexidade do processo saúde-doença e pela prática compromissada com a autonomia dos usuários ${ }^{(10)}$.

Num contexto em que a prática é atravessada pelo excesso de trabalho, pela lógica mecanicista e por concepções capitalistas, relegando a segundo plano o lugar da experiência e dos encontros, o PF foi capaz de "possibilitar novas formas de produção que geram potência de vida e de existência no mundo do trabalho, pautadas na cooperação entre todos que fazem acontecer as políticas de saúde"(16). O reconhecimento e a cooperação entre os profissionais demonstram que todos sabem algo (quando se veem produtores de conhecimento); governam, em certa medida (quando se sentem implicados na execução da política de saúde); e podem algo (quando identificam suas limitações e propõem novas formas de cuidado).

Estes avanços permitem problematizar que os ganhos identificados pelos participantes poderiam não ser apreendidos conceitualmente no rol de atividades de EPS, uma vez que permitiram um afloramento que extravasa os limites dos processos de EPS tradicionalmente conhecidos. O intercâmbio foi elemento mediador de um processo de apropriação pessoal do próprio trabalho, tomada de posição dentro da RAPS, reconhecimento do contexto e de elementos que influenciam a política de saúde mental no município, colocando a experiência como inovadora no sentido da capacidade de mobilização e ação na RAPS.

Assim, não se pode fazer uma associação causal entre o processo educativo como algo que liberta e emancipa por si só, ou que se trata de um processo homogêneo, que segue um fluxo ascendente de crescimento e desenvolvimento. O processo formativo é, também, algo da via da dicotomia e da tensão: liberta ao conscientizar, empodera ao desnudar as tensões entre teoria e prática, 
gestão e atenção, desejos de movimento e manutenção dentro da RAPS ${ }^{(22)}$.

Mesmo ao término do $\mathrm{PF}$, percebe-se que os profissionais persistem questionando-se, buscando aperfeiçoamento e garantia de direitos, perpetuando fluxos de desacomodação com potencial de seguir transformando realidades. Uma vez que foram produzidos também impactos no âmbito pessoal dos participantes, a experiência em questão alcança um patamar de inovação no âmbito das boas práticas de formação e atuação na prática, no ensino e na investigação em Saúde Mental, Álcool e Drogas.

A pesquisa contribui com o campo da enfermagem e da saúde, especialmente na área da saúde mental, na medida em que problematiza a relação entre as experiências de formação dos profissionais de saúde e processos de cuidado mais afeitos a uma produção de saúde crítica, reflexiva, criativa e emancipatória, considerando as tensões constitutivas deste encontro. Reitera-se a aposta de que um processo educativo - no seu sentido ampliado - quando emerge das necessidades dos trabalhadores e centraliza o lugar da experiência, é capaz de mobilizar e aquecer uma rede de atenção à saúde.

Além disso, com a crescente participação dos municípios na execução da política de saúde mental, impulsionada pela descentralização da saúde e pelo incentivo à implementação das redes, observa-se um incremento na quantidade e diversidade de pontos de atenção da RAPS implantados no Brasil. Esse processo vem acompanhado de uma tendência à interiorização da assistência em saúde mental para municípios de médio e pequeno portes, com forte participação da $A B$ no cuidado e valorização das ações territoriais e de base comunitária. Nesse cenário de expansão, ainda que permaneçam vazios assistenciais em saúde mental em certas regiões do país(23), dar visibilidade a projetos bem-sucedidos como o Percurso Formativo na RAPS, executado em municípios com características diversas, muitos deles de menor porte, afastados dos grandes centros urbanos e pouco conhecidos na esfera nacional, contribui para o aumento do protagonismo dos trabalhadores e gestores municipais frente aos novos desafios da RP brasileira.

Dentre as limitações identificadas, aponta-se a ausência de categorias profissionais que poderiam ter enriquecido o estudo, como agentes comunitários de saúde e médicos, que não participaram do intercâmbio em Guaíba. Ademais, a realização de quase todas entrevistas no ambiente de trabalho, por maior conveniência aos participantes, ainda que em espaços reservados e de forma sigilosa, poderia ter inibido as críticas ao projeto.
Muitos esforços foram empenhados visando garantir confiabilidade aos dados produzidos. O viés recordatório, no entanto, constitui outra possível limitação do estudo, considerando o período transcorrido entre o intercâmbio (2014-2015) e a coleta de dados (2016). Esse distanciamento temporal, por outro lado, indica que os dados revelados correspondem ao que foi mais marcante da experiência.

\section{Conclusão}

Os resultados evidenciam o desenvolvimento de forte e duradouro senso de crítica em relação às práticas de saúde mental mediante identificação de contrastes e semelhanças entre a situação de Guaíba e Santo André. O sentimento de necessidade de inovação foi impulsionados pelo projeto e parece ter voltado a emergir a partir da rememoração da experiência durante as entrevistas.

Mudanças nas concepções e práticas em saúde mental demandam esforços para sensibilizar diversos agentes envolvidos com o cuidado. Os encontros com colegas, usuários e instituições, oportunizado pelo intercâmbio, podem ser traduzidos em pujança, satisfação e potência dos afetos na consolidação do aprendizado.

O PF configura-se como estratégia que consolida a integralidade do cuidado, com base no atendimento adequado às necessidades e na humanização. Os resultados representam afloramento pessoal, profissional e de pertencimento à rede, impulsionando novas ações de EPS em Guaíba em diferentes direções. De outra parte, podem incentivar a organização de outras edições dessa proposta pelo MS.

A inovação, em suma, evidencia algo de entrelugares: não é possível educar profissionais sem considerar o contexto real dos cenários de saúde em que estão imersos; ao mesmo tempo, não é possível qualificar o trabalho na RAPS sem acreditar na potência da experiência como elemento pedagógico de auto implicação. Intercambiar fala disso: movimentar-se (na rede e com os outros), desprender-se, voltar, ressignificar, educar-se reciprocamente.

\section{Referências}

1. Lancetti A, Amarante P. Saúde Mental e Saúde Coletiva. In: Campos GWS, Minayo MCS, Akerman M, Drumond M Jr, Carvalho YM, organizadores. Tratado de Saúde Coletiva. São Paulo: Hucitec; Rio de Janeiro: Fiocruz; 2006. p. 615-34.

2. Amarante P, Torre EHG. Madness and cultural diversity: innovation and rupture in experiences of art and culture from Psychiatric Reform and the field of 
Mental Health in Brazil. Interface. 2017;21(63):76374. doi: http://doi.org/10.1590/1807-57622016.0881 3. Almeida JMC. Mental health policy in Brazil: what's at stake in the changes currently under way. Cad Saúde Pública. 2019;35(11). doi: http://doi. org/10.1590/0102-311×00129519

4. Ministério da Saúde (BR). Lei No. 10216 de 6 de abril de 2001. Dispõe sobre a proteção e os direitos das pessoas portadoras de transtornos mentais e redireciona o modelo assistencial em saúde mental [Internet]. Diário Oficial da União, 9 abr 2001 [Acesso 12 maio 2020]. Disponível em:http://www.planalto.gov.br/ccivil_03/ leis/leis_2001/l10216.htm

5. Onocko-Campos RT. Saúde mental no Brasil: avanços, retrocessos e desafios. Cad Saúde Pública. 2019;35(11). doi: http://doi.org/10.1590/0102-311×00156119

6. Ministério da Saúde (BR). Portaria GM No. 3088, de 23 de dezembro de 2011. Institui a Rede de Atenção Psicossocial para pessoas com sofrimento ou transtorno mental e com necessidades decorrentes do uso de crack, álcool e outras drogas, no âmbito do Sistema Único de Saúde (SUS). Diário Oficial da União, 30 dez 2011 [Acesso 12 maio 2020]. Disponível em: http://bvsms.saude.gov.br/bvs/saudelegis/gm/2011/ prt3088_23_12_2011_rep.html

7. Contandriopoulos A. Evaluating the institutionalization of evaluation. Ciênc Saúde Coletiva. 2006;11(3):705-11. doi: http://doi.org/10.1590/ S1413-81232006000300017

8. Weber L, Rosa RS. Avaliação da primeira etapa do projeto "Percursos Formativos na Rede de Atenção Psicossocial (RAPS): Intercâmbio entre experiências" no município de Guaíba/RS [dissertação]. Porto Alegre: Universidade Federal do Rio Grande do Sul; 2017.

9. Bardin L. Análise de Conteúdo. Lisboa: Edições 70; 2009.

10. Ministério da Saúde (BR). Política Nacional de Humanização [Internet]. Brasília: Ministério da Saúde; 2015 [Acesso 12 maio 2020]. Disponível em: http:// bvsms.saude.gov.br/bvs/folder/politica_nacional_ humanizacao_pnh_1ed.pdf

11. AFS Intercultura Brasil. A história do AFS [Internet]. [Acesso 13 jan 2017]. Disponível em: http://www.afs. org.br/sobre-o-afs/historia/

12. Organização Mundial de Saúde. Trabalhando juntos pela saúde: relatório mundial de Saúde 2006. Brasília: OMS; 2007 [Acesso 12 maio 2020]. Disponível em: https://www.who.int/ whr/2006/06_overview_pr.pdf?ua $=1$

13. Freire P. Pedagogia do Oprimido. 17a ed. Rio de Janeiro: Paz e Terra; 1987.

14. Maturana HR, Varela FJ. A árvore do conhecimento: as bases biológicas da compreensão humana. São Paulo: Palas Athena; 2010.
15. Carvalho MS, Merhy EE, Sousa MF. Rethinking Health policies in Brazil: Continuing Education in Health focused on meeting and knowing from experience. Interface. (Botucatu). 2019;23. doi: http://doi.org/10.1590/ interface. 190211

16. Vargas AFM, Campos MM. The trajectory of mental health policies and alcohol and other drugs in the twentieth century. Ciênc Saúde Coletiva. 2019;24(3):1041-50. doi: http://doi. org/10.1590/1413-81232018243.34492016

17. Assis JT, Barreiros CA, Jacinto ABM, Kinoshita RT, Macdowell PL, Mota TD, et al. Política de saúde mental no novo contexto do Sistema Único de Saúde: regiões e redes. Saúde Debate [Internet]. 2014 [Acesso 7 jul 2020];52:88-113. Disponível em: http://cebes.org.br/ site/wp-content/uploads/2014/12/Divulgacao-52.pdf 18. Assis JT, Scafuto JCB, Lenza RCP, Kinoshita RT. Percursos Formativos na RAPS: aprendendo e ensinando entre pares. In: Anais do $12^{\circ}$ Congresso Internacional da Rede Unida. 2016 21-24 Mar; Campo Grande, Brasil. 2016; 2(1). [Acesso 06 Maio 2020]. (Saúde em Redes, vol. 2, sup. 1). Disponível em: http://conferencia2016.redeunida.org.br/ocs/index. php/congresso/2016/paper/view/2654

19. Gaino LV, Souza J, Cirineu CT, Tulimosky TD. The mental health concept for health professionals: a cross-sectional and qualitative study. SMAD, Rev Eletrônica Saúde Mental Álcool Drog. 2018;14(2):10816. doi: http://doi.org/10.11606/issn.1806-6976. smad.2018.149449

20. Souza J, Almeida LY, Luis MAV, Nievas AF, Veloso TMC, Barbosa SP, et al. Mental health in the Family Health Strategy as perceived by health professionals. Rev Bras Enferm. 2017;70(5):935-41. doi: http://doi. org/10.1590/0034-7167-2016-0492

21. Silva DG, Brito JNPO, Fernandes MA, Almeida CAPL, Lago EC. Conception of Family Health Strategy Professionals on Mental Health in Primary Care. SMAD, Rev Eletrônica Saúde Mental Álcool Drog. 2017;13(3):118-24. doi: http://doi.org/10.11606/ issn. 1806-6976.v13i3p118-124

22. Leite CM, Pinto ICM, Fagundes TLQ. Permanent education in health: reproduction or counter-hegemony? Trabalho Educ Saúde. 2020;18(Suppl. 1):e0025082. doi: http://doi.org/10.1590/1981-7746-sol00250

23. Macedo JP, Abreu MM, Fontenele MG, Dimenstein $M$. The regionalization of mental health and new challenges of the Psychiatric Reform in Brazil. Saúde Soc. 2017;26(1):155-70. doi: http://doi.org/10.1590/ S0104-12902017165827

\section{Contribuição dos autores}

Concepção e desenho da pesquisa: Larissa Weber, Roger dos Santos Rosa, Marina da Silva Sanes, Jaime Alonso 
Caravaca-Morera. Obtenção de dados: Larissa Weber, Roger dos Santos Rosa. Análise e interpretação dos dados: Larissa Weber, Roger dos Santos Rosa, Marina da Silva Sanes, Jaime Alonso Caravaca-Morera. Redação do manuscrito: Larissa Weber, Roger dos Santos Rosa, Marina da Silva Sanes, Jaime Alonso Caravaca-Morera. Revisão crítica do manuscrito quanto ao conteúdo intelectual importante: Larissa Weber, Marina da Silva Sanes, Jaime Alonso Caravaca-Morera, Roger dos Santos Rosa.

Todos os autores aprovaram a versão final do texto. Conflito de interesse: os autores declararam que não há conflito de interesse.

Esta licença permite que outros distribuam, remixem, adaptem e criem a partir do seu trabalho, mesmo para fins comerciais, desde que the atribuam o devido crédito pela criação original. É a licença mais flexível de todas as licenças disponíveis. É recomendada para maximizar a disseminação e uso dos materiais licenciados. 